\title{
Making the Link between Health and Productivity at the Workplace - A Global Perspective
}

\author{
Wolf KIRSTEN ${ }^{1}$ \\ ${ }^{1}$ International Health Consulting, Holtzendorffstrasse 17, 14057 Berlin, Germany \\ Received November 2, 2009 and accepted February 2, 2010
}

\begin{abstract}
This paper discusses the relationship between health and productivity at the workplace by providing a global perspective of the current status of the fields of workplace health promotion and health management. The prevailing chronic disease trends coupled with economic pressures have proven a significant challenge for employers and employees alike. While a global growth trend in workplace health promotion can be observed the number of companies which take a proactive and integrated approach to workplace health remains small. Workplace health promotion programs in the United States typically focus on the individual health risks of employees while their European counterparts target work-related hazards, physical and, more recently, psychosocial. A number of specific tools and programs for integrated health management are described, such as self-report instruments to meausre presenteeism. The analysis suggests that exisiting occupational health services strategies are insufficient to address the current challenges. Improved employee health can only be achieved in a sustainable manner when integrating all health-related services within an enterprise and addressing psychosocial and organizational factors as well as individual health issues.
\end{abstract}

Key words: Workplace health promotion, Productivity, Presenteesim, Integrated health management, Psychosocial working environment

\section{Introduction}

Employers throughout the world are currently facing immense challenges: a global economic crisis, an increasingly fast-paced business environment, growing demands for increased productivity and last but not least an aging and seemingly unhealthy workforce. As chronic diseases are on the rise, e.g., heart disease, hypertension, diabetes, cancer, employees are becoming sicker and less productive. A report by the British health insurance provider BUPA $^{1)}$ paints a bleak picture of the future workforce. Employees will be older, with more long-term conditions or "lifestyle" conditions, caring for others, obese with diabeites and/or heart problems, in the kind of jobs more likely to have an impact on psychological health and working in knowledge-intensive or service industries. One could infer that this prediction applies globally with the current disease patterns being most pronounced in North America, Europe, and Japan.

E-mail: wk@wolfkirsten.com
The health of employees is rapidly becoming a key business factor, both from a cost and from an asset perspective. Employers have not succeeded in lowering health care costs through containment strategies due to the daunting demographic and disease trends. Coupled with growing demands for increased productivity in the global marketplace, employers are coming to terms with the fact that existing occupational health schemes are insufficient. Sick leave has become a huge problem. For example, 600 million working days are lost due to workrelated illness in Europe ${ }^{2)}$. The reasons are manifold: aging populations, increasing work-related stress and unhealthy behaviours. Employees are under tremendous pressure at the workplace as the overall economic environment is unfavorable and present working conditions have led to increased workloads and demands and reduced rewards and control. Productivity related costs of mental health disorders in the EU-25 (plus Norway, Iceland and Switzerland) have been estimated at $€ 136$ billion in $2007^{3)}$. The figure would be much larger when taking presenteeism into account. This has called for a more 
proactive, prevention focused approach to healthy workplaces which can be best described as workplace health promotion. The International Association for Worksite Health Promotion (IAWHP) defines workplace health promotion as "a corporate set of strategic and tactical actions that seek to optimize worker health and business performance through the collective efforts of employees, families, employers, communities, and society-at-large ${ }^{4) "}$. The World Health Organzation (WHO) takes a broader approach by defining a healthy workplace as one which considers the following 5 ):

- Health and safety concerns in the physical work environment;

- Health, safety and well-being concerns in the psychosocial work environment including organization of work and workplace culture;

- Health promotion opportunities in the workplace; and

- Ways of participating in the community to improve the health of workers, their families and other members of the community.

A growing number of organizations are adopting workplace health promotion strategies and programs as evidenced by a number of international surveys.

\section{A Closer Look at Global Trends}

The most extensive global survey available is "Working Well: A Global Survey of Health Promotion and Workplace Wellness Strategies" commissioned by Buck Consultants ${ }^{6}$. 1,103 organizations from 45 different countries responded to the survey, representing more than 10 million employees around the world. The survey, now in its $3 \mathrm{rd}$ $y r$, revealed a number of interesting trends in employersponsored health promotion and wellness programs:

1. $64 \%$ of the organizations surveyed indicate they have a wellness strategy (an increase from 60\% last year and $49 \%$ in 2007). However, among those employers with a wellness strategy, two-thirds have not yet completely implemented their strategy.

2. Among multi-national companies, $41 \%$ report having a global strategy and $46 \%$ having globally centralized ownership and responsibility for health promotion (increased from $22 \%$ in 2008).

3. Growth in health promotion offerings can be observed throughout the world with North America having the highest prevalence at $75 \%$ of participating employers offering a health promotion activity.

4. The number one strategic objective for offering a health promotion program in most regions of the world is improving productivity and presenteeism. Reducing heath care costs remains the top objective for US employers while improving workforce morale and engagement is a priority for Asian employers. Reducing employee absence was consistently among the top three objectives (Fig. 1).

5. With regard to the top health issues driving the content of programs stress was listed as the top issue in the majority of regions, only the United States and Latin America specify physical activity and exercise as number one.

6. The most popular health promotion program elements are biometric health screenings (such as blood pressure, cholesterol, body fat), health risk appraisals (health and lifestyle questionnaires) and executive screening programs, immunizations and gym or fitness club membership discounts.

7. Only $22 \%$ of surveyed organizations report measuring financial outcomes of their health promotion programs. This goes in line with the number of employers (from $33 \%$ to $47 \%$ ) who do not know the

\begin{tabular}{lccccccc}
\hline & Africa & Asia & Australia & Canada & Europe & Latin America & U.S. \\
\hline Improve productivity/presenteeism & 1 & 2 & 1 & 1 & 1 & 1 & 2 \\
Reduce employee absences & 2 & 3 & 2 & 2 & 3 & 3 & 3 \\
Improve workforce morale/engagement & 4 & 1 & 3 & 4 & 2 & 4 & 4 \\
Maintain work ability & 3 & 6 & 6 & 7 & 4 & 2 & 8 \\
Further organizational values/mission & 5 & 4 & 8 & 6 & 6 & 6 & 5 \\
Attract and retain employees & 6 & 7 & 4 & 5 & 5 & 7 & 7 \\
Improve workplace safety & 7 & 5 & 5 & 8 & 7 & 5 & 6 \\
Reduce health care/insurance costs & 9 & 9 & 11 & 3 & 11 & 11 & 1 \\
Promote corporate image or brand & 8 & 8 & 6 & 9 & 8 & 9 & 9 \\
Fulfill social/community responsibility & 10 & 10 & 8 & 10 & 9 & 8 & 10 \\
Comply with legislation & 11 & 11 & 10 & 11 & 10 & 10 & 11 \\
Supplement gov't-provided health care & 12 & 12 & 12 & 12 & 12 & 12 & 12 \\
\hline
\end{tabular}

Fig. 1. Top employer objectives driving health promotion initiatives from 2009 Buck Consultants report of working well: a global survey of health promotion and workplace wellness strategies. 
impact of their health promotion initiatives on their organization's strategic objectives.

8. Only one in four respondents indicated that the economic crisis has decreased their ability to provide health promotion services, $20 \%$ actually indicated an increased focus on such programs and services.

The survey supports similar findings of other smaller surveys ${ }^{7)}$ that employers worldwide are increasingly recognizing the value of employee health and well-being. This should not, however, deter us from the fact that still only a minority of companies globally in total are adopting a health promotion approach. There are still many companies, especially in developing countries and small employers, which have not implemented basic occupational health and safety services yet ${ }^{8}$.

\section{The Emergence of Presenteeism as a Target of Study}

While absenteeism figures are still highly popular as a human resources or business indicator, as highlighted in the Buck survey, these are difficult to trace back to health issues and automatically depressed in tough economic times. Therefore, employers have become interested in the measurement of presenteeism, i.e, to what degree employees are present at work but limited in their job performance by health problems (physical and mental). This presents itself with some challenges because objective measures of productivity are hard to come by in a service-oriented and knowledge-intensive working world. Nevertheless, the methods of measuring presenteeism have matured considerably over the last five years and a number of validated self-report surveys now exist, e.g. the Work Limitations Questionnaire (WLQ), the Stanford Presenteeism Scale (SPS) and the Health and Work Performance Questionnaire (HPQ). Respondents are asked to rate their level of difficulty or ability to perform specific job demands, e.g. physical, emotional or output demands ${ }^{9}$. Most of the presenteeism research comes out of the United States, in particular studies documenting the association between health risks and productivity. Burton, Chen, Conti et $a l^{10)}$. associated increases/decresases in health risks with increases/decresases in presenteeism. Using the Work Limitations Questionnaire the authors showed siginifcant linear trends of changed productivity associated with changes in health risks, i.e. productivity loss increased as health risks increased and productivity loss decreased as health risks decreased. A different study by Hertz, Unger and McDonald et al ${ }^{11)}$. made the link between obesity and work limitations and cardiovascular risk factors. Obese workers experience significantly higher rates of work limitations compared to normal weight workers. The effect was about the same magnitude as
$20 \mathrm{yr}$ of aging, i.e. the work limitations of younger obese workers was similar to those of middle-aged normalweight workers. These type of findings led companies to develop strategies to address the presenteeism challenge and actually measure the impact. Dow Chemical made an effort to examine the origins of their health-related costs with presenteeism included as a measure ${ }^{12)}$.

The survey of 12,397 employees found that for all chronic conditions studied, the cost associated with presenteeism greatly exceeded the combined costs of absenteeism and medical treatment combined - at least three times as much in all cases except diabetes (see Fig. 2). These innovative findings received attention from other leading employers and opened up a discussion on the feasibility of measuring presenteeism or productivity. The Harvard Business Review estimates that lost productivity due to presenteeism is, on average, 7.5 times greater than that lost to absenteeism and three times than that spent on direct medical costs ${ }^{13}$. The Sainsbury Centre for Mental Health in the United Kingdom suggests that productivity losses due to presenteeism may be between $50 \%$ to $500 \%$ greater than estimates of cost based on absenteeism alone ${ }^{14}$.

The link between health and performance is also being studied in Europe. The vielife health and performance research study demonstrated that a multi-component health promotion program improves both individual health status and work performance ${ }^{15}$. The prospective controlled study over 12 months documented a higher health and well being score, significant quality of life improvements as measured by the SF-36 questionnaire, and a $8.5 \%$ improvement in work performance (as measured by the Health and Work Performance Questionnaire) in the

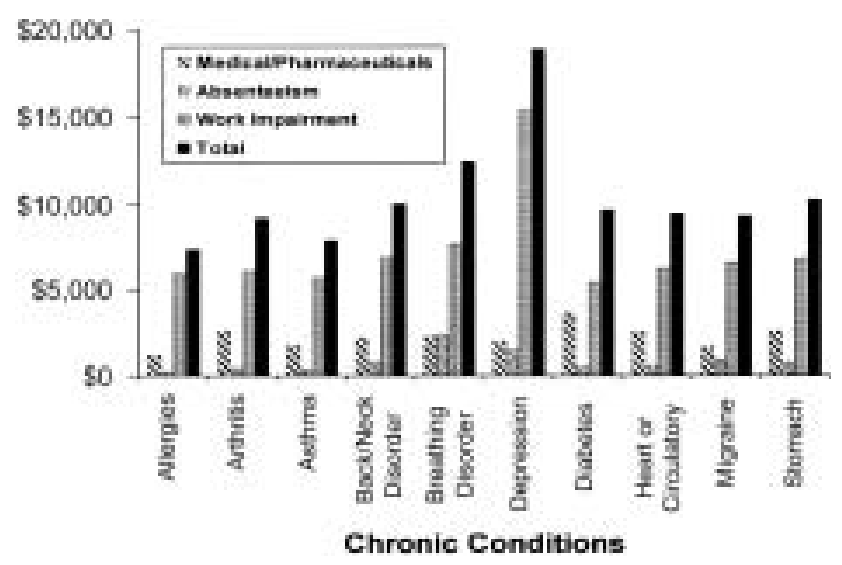

Fig. 2. Dow Chemical Assessment of Chronic Health Conditions on Work Performance, Absence and Total Economic Impact for Employers (2005) from J Occup Environ Med (2005) 47, 547-57. Absence: self-reported absence based on Stanford Presenteeism Scale. Work impairment: level of presenteeism -lost productivity that occurs when employees come to work but perform below par due to any kind of illness- calculated by the Stanford Presenteeism Scale. 
intervention group. An annual return-on-investment (ROI) of $£ 3.73$ for every $£ 1$ spent was estimated. In spite of the existing research and surveys a degree of skepticism remains among the medical community and decision-makers in light of the self-report data.

\section{The Tools of Integrated Health Management}

Making the link between employee health and productivity is a necessary step to assess the full impact of poor health, but the next step is even more important: to improve the health of employees, provide good working conditions and with that increase morale, motivation and performance. This is only possible on a sustainable basis with an integrated health management approach. The aim of health management is to measurably improve total health -and with that productivity and performance- and reduce health-related costs. Health management includes an integrated collection of data and delivery of services across the "silos" of health promotion, occupational health, disease management, workers compensation and disability case management. This presents a considerable challenge for employers, especially in large multi-national corporations where a number of different departments exist dealing with health-related issues. One of the most important principles in health management is to address the health of all employees, not only the sick and disable ones. Unfortunately, most employers still only focus on the employees who are on sick leave and short- or longterm disability with the goal of re-integrating them into the work process. This thinking neglects the fact that employees who are low-risk move into the medium- or high-risk categories and in the end, you have more people who became high-risk than people who reduced their risk $^{16)}$. This goes back to the prevailing thinking that health equals the absence of disease.

A growing number of employers are beginning to look at energy, vitality and well-being as essential elements of health. This concept can be traced back to Antonovsky's 1979 publication "Health, Stress and Coping" in which he describes the term "salutogenesis" which focuses on factors that support human health and well-being, rather than on factors that cause disease ${ }^{17)}$. The different approaches -a biomedical risk-based approach focused on the individual versus a psychosocial approach focused on the working environment- are emphasized in varying degrees depending on the country or region. The United States have a long tradition in workplace health promotion programming focusing on reducing invidiual health risks coupled with extensive research on the health and cost benefits ${ }^{18)}$. Most European countries, in particular in Scandinavia, have been analyzing psychosocial factors of work and how these affect employee health, e.g. work organization, employee relations and work climate. Most psychosocial approaches seem have been mired in the analytical stages and practically-oriented programs impacting change are far and few between.

A promising example for operationalizing a healthy psychosocial working envrionment are the Management Standards for work-related stress developed by the United Kingdom Health and Safety Executive ${ }^{19}$. The Management Standards cover six key areas of work design that, if not adequately managed, are associated with poor health and well-being, lower productivity and increased sickness absence: demands, control, support, relationships, role and change. The standards require companies to conduct risk assessments and create action plans to improve conditions. The threat of litigation under the UK Health and Safety at Work legislation is also an incentive for employers to start addressing the issue of work-related stress. Developing stress-related illness is increasingly seen as a work hazard.

The European Network for Workplace Health Promotion (ENWHP) has also made it a priority of bringing mental well-being and health promotion closer to the working world ${ }^{20)}$. The 8th ENWHP initiative is titled "Work in Tune with Life". This includes a mental health check which employers are encouraged to complete in order to assess the quality of mental health promotion measures in the organization. Companies can become a "Move Europe Partner", a good practice model and ultimately win an award at the end of the 3-year campaign.

\section{The Worker's Responsibility to Stay Healthy}

While focusing on how work affects health has a longstanding tradition and is now gradually shifting from physical towards psychosocial risks in industrialized countries one cannot afford to neglect the implications of how health affects work. The individual worker needs to take responsibility for his or her own health and solely rely on the health care system and the employer. Of course, the individual cannot be expected to achieve a transformation towards a healthier lifestyle on his or her own. Next to a good working environment, the employer, and society at large, should provide information, resources, and policies to enable behavior change. Typically, workers will welcome assistance and guidance for the improvement of their health as they directly benefit from these, also in their personal life. Unfortunately, high-profile cases of corporations misusing personal employee data have recently surfaced in Europe making it more difficult to engage the employee, and employee representative councils, on a personal issue such as health ${ }^{21)}$. Employees are concerned about "giving away" personal health data even if data privacy is secured and communicated. In addition, individual cases of American 
employees being penalized for specific health behaviors, e.g. fired for smoking, have received strong media attention and misrepresent the field of workplace health promotion $^{22)}$. This will remain a crucial challenge for workplace health professionals in the near future.

\section{Conclusion}

This article outlines a global growth trend in workplace health promotion as well as a gradual convergence of various health promotion approaches. From an employer perspective, the issue of productivity is as important as ever, however, recognizing the enormous potential of employee health in improving productivity is more of a recent phenomenon. Instruments to measure presenteeism have matured and a multitide of research studies on the impact of ill-health or health risks on productivity have been published. Generally still lacking are successful health promotion programs and intervention studies documenting how productivity can be increased through comprehesive and sustainable programs. Innovative and award-winning programs ${ }^{23}$ ) include two main features in order to achieve good health for the employees and increased productivity:

1. an integrated health management approach breaking down existing silos;

2. a holistic approach addressing psychosocial factors as well as individual health issues.

\section{References}

1) BUPA (2009) Healthy work - Challenges and opportunities to 2030.

2) European Agency for Safety and Health at Work (2000) Research on work-related stress. European Communities, Luxembourg.

3) McDaid (Ed.) (2008) Mental health in workplace settings consensus paper. European Communities, Luxembourg.

4) International Association for Worksite Health Promotion Atlanta Announcement on Worksite Health Promotion 2009. http://www.acsm-iawhp.org/files/ AtlantaAnnouncement.pdf. Accessed October 19, 2009.

5) World Health Organization (WHO). Healthy workplace framework. http://www.who.int/entity/occupational_health/ global_framework_for_health_workers.pdf. Accessed October 20, 2009.

6) Buck Consultants (2009) Report of working well: a global survey of health promotion and workplace wellness strategies. Buck Consultants, San Francisco.

7) Watson Wyatt Worldwide Research Report: adopting a global health care benefits strategy: 2006 Survey of multinationals on health care. http://www.watsonwyatt. $\mathrm{com} / \mathrm{research} / \mathrm{resrender}$. asp $? \mathrm{id}=\mathrm{W}-916 \& \mathrm{page}=1$. Accessed October 20, 2009.
8) Jamison DT, Alleyne G, Breman JG, Claeson M, Evans D, Jha P, Measham AR, Mills A, Musgrove P (Eds.) (2006) Disease Control Priorities in Developing Countries, 413-32, Oxford University/Press/World Bank, Washington, DC.

9) Tufts Medical Center, Institute for Clinical Research and Health Policy Studies. The Work Limitations Questionnaire. http://160.109.101.132/icrhps/resprog/thi/ wlq.asp. Accessed October 25, 2009.

10) Burton WN, Chen CY, Conti DJ, Schultz AB, Edington DW (2006) The association between health risk change and presenteeism change. J Occup Environ Med 48, 252-63.

11) Hertz RP, Unger AN, McDonald M, Lustik MB, Biddulph-Krentar, J (2005) The impact of obesity on work limitations and cardiovascular risk factors in the U.S. workforce. J Occup Environ Med 46, 1196-203.

12) Collins J, Baase $C$, Sharda $C$, Ozminkowski RJ, Nicholson S, Billotti GM, Turpin RS, Olson M, Berger ML (2005) Assessment of chronic health conditions on work performance, absence and total economic impact for employers. J Occup Environ Med 47, 547-57.

13) Hemp P (2004) Presenteeism: at work- but out of it. Harvard Bus Rev, October 2004, 1-10.

14) Sainsbury Centre for Mental Health (2007) Mental health at work: developing the business case. Sainsbury Centre for Mental Health, London.

15) Mills PR, Kessler RC, Cooper J, Sullivan S (2007) Impact of a health promotion program on employee health risks and work productivity. Am J Health Promot 22, 45-53.

16) Wellness Councils of America (Welcoa) Expert Interview with Dee Edington (2004) www.welcoa. org/freeresources/pdf/Edington_INTERVIEW_1.pdf. Accessed October 19, 2009.

17) Antonovsky A (1979) Health, stress and coping. JosseyBass Publishers, San Francisco.

18) Aldana $S$ (2001) Financial impact of health promotion programs: a comprehensive review of the literature. Am J Health Promot 15, 296-320.

19) United Kingdom Health and Safety Executive. Management standards for work-related stress. http://www. hse.gov.uk/stress/standards. Accessed October 30, 2009.

20) European Network for Workplace Health Promotion (2009) Work in tune with life. http://www.enwhp.org/ enwhp-initiatives/current-initiative-work-in-tune-withlife.html. Accessed October 20, 2009.

21) Tagesspiegel: Daimler speicherte heimlich Krankendaten (2009) http://www.tagesspiegel.de/wirtschaft/UnternehmenDaimler-Benz-Datenskandel;art129,2774480. Accessed January 27, 2010 (in German).

22) MSNBC: Fired for smoking? (2005) http://www.msnbc. msn.com/id/6870458/. Accessed January 27, 2010.

23) Dow Chemical News Center. Dow Receives 2008 C. Everett Koop award national health award from the health project. http://news.dow.com/corporate/2008/ 20080925a.htm. Accessed October 28, 2009. 